\title{
Contingencies in the relationship between economic freedom and human development: the role of generalized trust
}

\author{
Johan Graafland* \\ Department of Economics, Tilburg University; CentER, 5000 LE Tilburg, The Netherlands \\ *Corresponding author. Email: j.j.graafland@uvt.nl
}

(Received 12 April 2019; revised 17 September 2019; accepted 23 September 2019; first published online 7 November 2019)

\begin{abstract}
An increasing volume of literature has shown that human development is related to economic institutions. But previous literature has not considered that the effects of economic institutions on human development are contingent on culture. In this study, we contend that the effects of economic freedom (as an indicator of economic institutions) on human development are dependent on generalized trust (as an indicator of culture). Using panel analysis on a sample of 29 OECD countries during 1990-2015, we find that generalized trust positively moderates the relationship between economic freedom and human development. The policy implication is that free market institutions foster human development only in high trust societies, not in low trust countries.
\end{abstract}

Keywords: Economic freedom; human development; interaction; generalized trust

\section{Introduction}

Human development has been shown to be dependent on institutions (Nikolaev, 2014) and culture (Guiso et al., 2006). Whereas previous literature has researched the isolated influences of institutions and culture on human development, recent theoretical studies have considered that the influence of institutions may be contingent on culture (Bisin and Verdier, 2017; Bowles, 2011; Masten and Prüfer, 2014; McCannon et al., 2018). Yet no empirical studies have been done into the interactive effects of institutions and culture on human development. The central research question of this paper is therefore: How does the impact of institutions on human development depend on culture?

The concept of institutions has been famously defined by North (1991: 97) as "the humanly devised constraints that structure political, economic and social interactions." In his definition, North includes both formal institutions, which refer to rules, laws and constitutions created and codified by the polity, as well as informal institutions, which consist of (mostly uncodified) norms of behavior, taboos, traditions, convention, and self-imposed codes of conduct. For North, informal institutions are part of culture. Indeed, "norms" and "conventions" are also defining characteristics of the concept of culture. Culture refers to decision-making heuristics, which typically manifest themselves as values, beliefs, or social norms. ${ }^{1}$ Or, in the words of Guiso et al. (2006: 23) "those customary beliefs and values that ethnic, religious, and social groups transmit fairly unchanged from generation to generation."

Alesina and Giuliano (2015) have argued that North's definition of institutions is problematic, because the overlap in the meaning of institutions and culture hinders an unambiguous measurement of both

\footnotetext{
${ }^{1}$ See Alesina and Giuliano (2015: 901, note 5), where they cite Boyd and Richerson (2005).

(c) Millennium Economics Ltd 2020. This is an Open Access article, distributed under the terms of the Creative Commons AttributionNonCommercial-NoDerivatives licence (http://creativecommons.org/licenses/by-nc-nd/4.0/), which permits non-commercial re-use, distribution, and reproduction in any medium, provided the original work is unaltered and is properly cited. The written permission of Cambridge University Press must be obtained for commercial re-use or in order to create a derivative work.
} 
concepts and the analysis of the interaction between them. They therefore propose to limit the concept of institutions to formal institutions, leaving out the overlapping part of informal institutions. For the purpose of our analysis of the interacting influences of institutions and culture on human development, this modification is very helpful. Following Alesina and Giuliano (2015) we will therefore, for brevity, refer to formal institutions (defined as rules, laws and constitutions created and codified by the polity) simply as institutions, and to culture as (mostly uncodified) customary beliefs, values and other norms.

Institutional literature has distinguished between economic and political institutions (Alesina and Giuliano, 2015). In this paper, we focus on economic institutions that generate economic freedom. Economic freedom refers to the degree of personal choice, voluntary exchange, freedom of competition, and protection of privately owned property afforded by society (Gwartney et al., 2017). An extensive volume of studies has shown that economic freedom is related to GDP per capita or economic growth (Azman-Saini et al., 2010; Bennett et al., 2017; De Haan et al., 2006; Farhadi et al., 2015; Hall and Lawson, 2014; Hall et al., 2010; Justesen, 2008; Murphy, 2016; Spruk and Kešeljević, 2018). Other studies have found that economic freedom is positively related to education (Aixalá and Fabro, 2009; Feldmann, 2017; King et al., 2012; Schofer and Meyer, 2005) and health (Stroup, 2007). It is therefore expected that economic freedom will positively relate to human development as measured by the human development index (HDI), which combines a long and healthy life, access to knowledge, and a decent standard of living as a proxy of the formation of human capabilities and the choices people have in putting their capabilities to use. Empirical research by Nikolaev (2014) confirmed a positive relationship between economic freedom and the HDI on a sample of 87-129 countries for the period 1980-2010.

Discussion of the economic impact of culture is crystallizing in the concept of social capital. This stands for "features of social organization, such as networks, norms, and trust that facilitate coordination and cooperation for mutual benefit" (Putnam 1993: 2). One of the most important dimensions of social capital is generalized trust (Fukuyama, 1995). The economic importance of generalized trust (e.g. trusting most people you do not know) for economic growth has been established by empirical research (Algan and Cahuc, 2014; Berggren and Jordahl, 2006; Bjørnskov, 2012; Knack and Keefer, 1997). As trust has also been shown to be positively related to education (Bjørnskov, 2012; Papagapitos and Riley, 2009) and health (Berggren and Jordahl, 2006; Jen et al., 2010; Rostila, 2007), it is likely that it correlates with human development as well. This is confirmed by Özcan and Bjørnskov (2011), who found that trust is positively related to the HDI.

In this paper, we contend that the effect of economic freedom on human development is dependent on generalized trust. On one hand, it can be argued that the opportunities provided for commerce by a more economically free society will only be realized if people trust each other. If people do not trust other people, they might be less likely to cooperate (Balliet and Van Lange, 2013; Gächter et al., 2004) and make use of the opportunities that arise from more economic freedom. This would imply that the influence of economic freedom on human development is strongest if trust is high, suggesting complementarity between institutions and culture. On the other hand, it can be argued that free market institutions economize on trust. By defining and enforcing property rights, economic freedom may decrease the scope of trust. Then it would be suggested that the influence of free market institutions on human development is strongest if trust is low and that institutions substitute for culture.

The current paper contributes to the literature by testing the new hypothesis that the relationship between economic freedom and human development is contingent on generalized trust, using panel analysis with fixed effects for 29 OECD countries during 1990-2015. The results have potentially important policy implications. For example, if it turns out that the positive influence of economic freedom on human development depends positively on generalized trust, the liberalization of markets will contribute to human development in a high trust society. But in a low trust society, such policies may have detrimental effects on human development, because the imperfections that come with free markets may then generate high transaction costs.

In what follows (section 2), we first present the literature review and the hypotheses of our study. Then (section 3) we discuss the methodology of the research. Section 4 reports the findings of the regression analysis and in the last section, we summarize the main conclusions and policy implications. 


\section{Literature review and hypotheses}

In this section we discuss the relationship between economic freedom and the HDI. The HDI captures three essential components of human development: a long and healthy life, access to knowledge, and a decent standard of living (Nikolaev, 2014). The HDI provides a more encompassing measure of overall development than GDP per capita, since information on health and education are added to the wellknown GDP statistics (Özcan and Bjørnskov, 2011). Following the capability approach of Sen (1984), it attempts to track the capabilities of people to exercise their freedom in order to attain a better life. Although the HDI does not account for other important dimensions of human life, it is nevertheless the best measure for allowing comparison of a large number of countries over a long period of time (Nikolaev, 2014). Below, we first describe the relationship between economic freedom and the HDI. Next, we will argue that the relationship between economic freedom and the HDI is likely to be contingent on generalized trust. Then the model specification is presented.

\section{Economic freedom and human development}

An important characteristic of economic institutions is the extent to which they promote economic activity to be coordinated by "personal choice, voluntary exchange, open markets, and clearly defined and enforced property rights," or in other words, economic freedom (Gwartney 2009: 939). Organizations such as the Fraser Institute annually publish indexes of economic freedom, distinguishing several aspects such as low government spending and low taxes, protection of property rights, sound monetary policy, free trade and low regulatory stringency of product, labor, and credit markets (for more details, see Table A2).

The literature has argued that economic freedom stimulates GDP per capita. A small government size and low taxes can lead to more efficient allocation of resources (Graafland and Compen, 2015). A good legal system that secures property rights and contracts provides incentives for innovation, as the protection of property rights ensures that entrepreneurs can reap the fruit of their labor (Nyström, 2008). Property rights ensure that the gains from the trade flow to the investor, which stimulates investments. Moreover, the enforcement of contracts makes it easier to access credit markets, which also fosters investment (Farhadi et al., 2015). Stable prices due to sound monetary policy can reduce uncertainty and foster entrepreneurship (Bjørnskov and Foss, 2008), while trade openness can provide opportunities for economies of scale and facilitate exchange of knowledge (Lucas, 2000). Government regulation may take insufficient account of economic dynamics and cause market rigidity (Friedman, 1999). Various empirical studies have indeed shown economic freedom is positively related to economic growth or GDP per capita (Azman-Saini et al., 2010; Bennett et al., 2017; De Haan et al., 2006; Farhadi et al., 2015; Hall et al., 2010; Justesen, 2008; Murphy, 2016; Spruk and Kešeljević, 2018).

A few studies have shown that economic freedom is also correlated with the HDI that combines income with education and life expectancy (as an indicator of health). Nikolaev (2014) analyzed the relationship between economic freedom and human development for more than 100 countries for the period 1980-2010. He found that positive changes in economic freedom are related to positive changes in human development.

These findings are supported by other studies that have addressed the relationship between economic freedom and education (Schofer and Meyer, 2005). Using data from 1972 to 2011 for 109 countries, Feldmann (2017) found a positive relationship between economic freedom and human capital investment. Secure property rights, a low level of taxation, and monetary stability protect economic agents from expropriation and create an incentive to invest in human capital. They also enhance the gains from economic exchange, incentivizing individuals to maximize the return on their human capital. Furthermore, economic freedom stimulates investment in education by facilitating the operation of credit markets. Similar results were found by Stroup (2007), Aixalá and Fabro (2009), and King et al. (2012).

As economic freedom has been found to relate to income, and income to health (Frijters et al., 2005; Gardner and Oswald, 2007), it is expected that economic freedom is also positively related to 
life expectation, the third dimension of the HDI. Stroup (2007) argued that the increase in a market place's effectiveness due to economic freedom will not only lead to greater prosperity, but also to choices by individuals that enable them to live longer, healthier lives. Using panel data analysis on a sample of 104 countries during five periods of time (1980, 1985, 1990, 1995, and 2000), he found that economic freedom is positively related to health.

\section{Moderation by generalized trust: three alternative hypotheses}

Whereas previous studies tested the influence of economic institutions on economic development, recent theoretical studies have started to analyze the interactive effects of institutions and culture on economic growth (Bisin and Verdier, 2017; Bowles, 2011; Masten and Prüfer, 2014). For example, Bisin and Verdier (2017) argued that the effects of institutions on economic growth depend on the presence of appropriate cultural traits. Experimental research by McCannon et al. (2018) showed a significant interaction effect between trust and contract enforcement in fostering contract formation. Also literature on interorganizational governance has shown that legal contracts and so-called relational governance (which includes trust) act as complementary (Arranz and Arroyabe, 2012; Poppo and Zenger, 2002). ${ }^{2}$ When contract enforcement is greater, people are more likely to enter into an agreement, and this probability increases when people exhibit high rather than low levels of trust. These findings indicate that trust and contract enforcement are complements rather than substitutes. In this section, we build on this new avenue of research and will argue that the effects of economic freedom on human development are likely to be contingent on generalized trust. In other words, we contend that generalized trust moderates the relationship between economic freedom and human development. Moderation means that the influence of an independent variable on a dependent variable is conditional on a third variable (the moderator) (Preacher et al., 2007). ${ }^{3}$

Trust can be defined as a psychological state comprising the intention to accept vulnerability based on positive expectations of the intentions or behavior of another person (Rousseau et al., 1998). The literature distinguishes between particularized trust and generalized trust (Berggren and Jordahl, 2006). The former entails trusting people you know, the latter trusting most people you do not know. Generalized trust indicates an inclusive and tolerant approach to the population at large and is considered to be at the heart of social capital. Generalized trust fosters so-called bridging social capital, which refers to the connections between dissimilar people (Jen et al., 2010).

Trust is an important factor in well-functioning cooperative relationships (Gächter et al., 2004; Balliet and Van Lange, 2013) and is the glue that builds and maintains longer-term relationships between buyers and sellers (Weitz and Bradford, 1999). It is a precondition for social order and social cohesion, without which many forms of social interaction are much more difficult (Bjørnskov, 2007; Helliwell and Putnam, 2004). In an economically free society, there are potentially more opportunities for commerce. Globalization through freeing markets from trade limitations provides more chances of economic interactions with more distant players (Tabellini, 2008). But the extent that people or companies make use of these potential opportunities is dependent on trust. In order to benefit from these opportunities, it is important that people have generalized trust in distant trade partners (Alesina and Giuliano, 2015).

\footnotetext{
${ }^{2}$ Jiang et al. (2013) made a distinction between "goodwill trust" and "competence trust" and found that competence trust complements formal contracts, whereas goodwill trust substitutes for formal contracts.

${ }^{3}$ Suppose that $Y=\alpha X M+\beta X+\gamma M$, where $Y$ is the dependent variable and $X$ the independent variable. Then $M$ is called the moderator. Following Arranz and de Arroyabe (2012) and Jiang et al. (2013), we interpret $\alpha>0$ as an indication that $X$ and $M$ are complementary factors. If $\alpha<0$, we interpret $X$ and $M$ as substitutes. The moderation model differs from the so-called mediation model, which is specified as: $Y=\alpha M ; M=\beta X$. If $\alpha \beta$ is significant, $M$ is called the mediator in the relationship between $X$ and $Y$. An example of a mediation model is the model estimated by Cruz-García and Peiró-Palomino (2019). In their model, $Y$ is credit ratio, $M$ is legal quality, and $X$ is social trust. Another example is Poppo and Zenger (2002), who define complementarity (substitution) as contracts and relational governance mutually positively (negatively) affecting each other (which diverts from our approach).
} 
Trust is particularly important due to the existence of information asymmetries that create moral hazard. Market parties then face the risk that the other party may harm their interests. If people do not trust other people, they will be less likely to cooperate and avail themselves of the commercial gains that economic freedom creates. Although formal contracts specify the duties of both parties, along with penalties for agreement violation, it is often impossible to have a complete contract governing partners' exchanges and relationships in an agreement (Arranz and de Arroyabe, 2012). Trust will safeguard against hazards that are poorly protected by the contract and help overcome the adaptive limits of contracts (Poppo and Zenger, 2002). It lowers bargaining, monitoring, and policing costs, thereby increasing economic efficiency and stimulating collective investments in innovation, education, and health. In the absence of trust, transaction costs may become very high and many opportunities for mutually beneficial cooperation may be foregone. This complementary relationship may also function in reverse in the sense that formal contracts complement generalized trust. High trust can lead to "blind faith" that exposes the trusting party to malfeasance of the contract partner. In that case, formal contracts could counter the breach of trust, because they specify a clear scope of the alliance activities, regulate the basic behaviors of partner firms, and specify severe punishments for opportunistic behaviors (Jiang et al., 2013). Therefore, we expect there to be some complementary or synergic effect when both economic freedom and generalized trust are high. This implies that the positive effects of economic freedom on human development are likely to be stronger when people trust each other. If there is no trust, an economy relies better on government regulation. Fukuyama (1995) postulates that people who do not trust each other only cooperate under a system of formal rules. Therefore, it might be beneficial to set up a system of formal regulatory rules (i.e. less economic freedom) when economic activity is inert to increases in freedom.

Based on these arguments, we predict that:

Hypothesis 1: The relationship between the human development index and economic freedom is positively moderated by generalized trust.

Hypothesis 1 implies that economic freedom and generalized trust are complementary: they reinforce each other in fostering human development. Another branch of literature has argued, however, that institutions and culture can also function as substitutes (Ahlerup et al., 2009; Jiang et al., 2013; Knack and Keefer, 1997; Masten and Prüfer, 2014; Poppo and Zenger, 2002). When pro-social behaviors are not prevalent and generalized trust is low, economic agents can rely on formal contract arrangements to facilitate trade (McCannon et al., 2018). By comparison with other allocation mechanisms (for example, gift exchange or central planning), markets may function tolerably well in the absence of trust. A well-ordered legal system that protects property and contract rights increases the cost of opportunistic behavior, assuring people that self-interested trade partners are not likely to exploit them. The advantages of free market institutions then substitute for the benefits of trust (Bowles, 2011) and economize on virtues such as honesty (Hayek, 1948). By defining and enforcing property rights, economic freedom thus obviates the need for trust. This substitution relationship may also function in reverse: by reducing transaction costs, generalized trust may replace "contracts with handshakes." If one party trusts the other, there is simply little need for contractually specifying actions (Poppo and Zenger, 2002).

This leads to an alternative hypothesis in which the strength of the effect of economic freedom on human development is negatively related to generalized trust: if generalized trust is low, there is more need of free market institutions, whereas if trust is high, there is less need for free market institutions. Hence an increase in economic freedom will have a stronger effect on human development if generalized trust is low. If generalized trust is high, it substitutes for economic freedom and an increase in economic freedom will only have minor effects on human development:

Hypothesis 2: The relationship between the human development index and economic freedom is negatively moderated by generalized trust. 
Lastly, one could also argue that the relationship between economic freedom and human development is independent from generalized trust. This possibility arises if generalized trust not only increases the efficiency of market operation, but also fosters the efficiency of government intervention and regulations. In a more trustworthy country, government members are also more likely to be trustworthy and less inclined to abuse their position for personal benefits (Cruz-García and Peiró-Palomino, 2019), and this increases the efficiency of government actions. Moreover, if trust is high, citizens are more likely to comply with tax regulations, because they believe that others will also do so (Rothstein, 2000). The implementation costs of government policies and regulations are lower where trust is high, as there is no need to create and maintain complex systems of supervision. An example is given by Putnam (1993), who described a nationwide institutional reform in Italy at the beginning of the 1970s that established regional governments across the country. Although the institutions were virtually equal in setup, the efficiency of these government institutions differed vastly between different regions. The regions endowed with high levels of social capital had superior outcomes regarding all kinds of government services (job-training centers, day-care structures), investment, and environmental standards, compared with those without it. Hence, generalized trust not only enhances the efficiency of free markets, but also the efficiency of government actions and regulations. As a result, the effect of an increase in economic freedom (e.g. reduction in government intervention) on human development might be independent of the level of trust.

Hypothesis 3: The relationship between the human development index and economic freedom is independent of generalized trust.

\section{Model specification}

Based on the previous sections, we propose the following model:

$$
\mathrm{HDI}_{\mathrm{i}, t}=\alpha+\beta \mathrm{EF}_{i, t} * \mathrm{GT}_{i, t}+\gamma \mathrm{EF}_{i, t}+\delta \mathrm{GT}_{i, t}+\sum \varepsilon_{k} \mathrm{X}_{i, k}+\sum \zeta_{n} \mathrm{Z}_{i, n, t}
$$

HDI denotes the human development life index, EF economic freedom, GT generalized trust, $X(k)$ time-invariant control variables, and $Z(n)$ time-variant control variables. The index i denotes country and $t$ denotes year. The hypotheses are tested by estimating coefficient $\beta$. If $\beta>0$, the results would provide support for hypothesis 1 , meaning that trust and economic freedom are complementary. If $\beta<0$, hypothesis 2 is supported, meaning that trust and economic freedom are substitutes. If $\beta=0$, hypothesis 3 is supported, meaning that the influence of economic freedom on human development is independent from generalized trust.

In order to test for moderation, we should control for the linear influences of economic freedom and generalized trust (Preacher et al. 2007). Therefore, we add linear economic freedom and generalized trust as control variables in the model specification. As time invariant controls, we included geographical factors, regional dummies for Nordic and post-communist countries, a dummy for monarchy, and dummies for religions (Bjørnskov et al., 2008; Feldman, 2017; Hofstede et al., 2010; Özcan and Bjørnskov, 2011). As geographical variables we used the internal distance (an often-used measure of average distance between producers and consumers in a country) (Mayer and Zignago, 2011) and temperature (Bjørnskov et al., 2008). As time-variant dummies we included political rights and civil liberty, urbanization, the share of the labor force employed in the industrial sector, female labor participation rate, and age structure (Bennet and Nikolaev, 2017; Feldmann, 2017; Graafland and Lous, 2018; Leigh, 2006).

As a robustness test, we also estimated a simpler specification of the model, which we will test for two different samples, one consisting of high trust countries $\left(\beta_{h}\right)$ and one of low trust countries $\left(\beta_{l}\right)$ :

$$
\begin{aligned}
& \mathrm{HDI}_{i, t}=\alpha+\beta_{h} \mathrm{EF}_{i, t}+\sum \varepsilon_{k} \mathrm{X}_{i, k}+\sum \zeta_{n} \mathrm{Z}_{i, n, t} \\
& \mathrm{HDI}_{i, t}=\alpha+\beta_{l} \mathrm{EF}_{i, t}+\sum \varepsilon_{k} \mathrm{X}_{i, k}+\sum \zeta_{n} \mathrm{Z}_{i, n, t}
\end{aligned}
$$


In this model, hypothesis 1 is supported if $\beta_{h}$ is significantly higher than $\beta_{l}$, hypothesis 2 is supported if $\beta_{h}$ is significantly lower than $\beta_{l}$, and hypothesis 3 is supported if $\beta_{h}$ does not significantly differ from $\beta_{l}$.

\section{Complication: the link between generalized trust and economic freedom}

We end this theory section by highlighting a complication that we have bypassed till now concerning the interdependency between generalized trust and economic freedom, and addressing the implications for our research. Generalized trust is based on a mixture of control, with dimensions as legal enforcement, and personal characteristics grounded in people's emotional bonds and moral attitudes, including civic virtues such as trustfulness, integrity, honesty, reliability, and justice (see also Beugelsdijk, 2006). A well-developed legal system that protects property rights and enforces contracts in a free economy reinforces a climate of generalized trust because there is every reason to believe that the chance of people getting away with deceiving others is small. Although generalized trust as a concept is distinct from control (and hence from various elements of economic freedom), it is likely to be highly related to the institutional context. If there is little variance in micro sources relating to personal characteristics between different countries and over time, generalized trust might empirically be largely determined by institutional differences and this might bias the results due to multicollinearity between economic freedom and generalized trust. In sections 3 and 4 we will therefore analyze the degree of correlation between economic freedom and generalized trust.

\section{Methodology}

\section{Measurement and data sources}

For reasons of comparability and availability of data, we created a sample of 29 OECD countries (see Table A1, only for these countries is data for trust available for several years) covering the period from 1990 to 2015.

We used the Human Development Index of the United Nations Development Program (UNDP), consisting of the logarithm to GDP per capita, life expectancy at birth, the adult literacy rate, and school enrolment ratios. The last two variables are combined into the education sub index. The HDI is a geometric mean of the normalized indices in each one of these three dimensions of human development.

Following most literature, we used the Economic Freedom of the World Index (EFWI) by the Fraser Institute as a measurement of economic freedom (Gwartney et al., 2017). ${ }^{4}$ In total the index covers 42 variables. The variables are weighted equally and aggregated into an average score that ranges from 1 being least free to 10 being most free.

For general trust, we used the well-known trust data of the World Value Survey (WVS) and European Value Survey (EVS) and measure generalized trust as the share of respondents in each country answering yes to the question "In general, do you think most people can be trusted?", which is a standard approach in the literature. This measure has proved to be a valid and powerful measure of social trust when assessed at the national level (Özcan and Bjørnskov, 2011). A recent study by Aksoy et al. (2018) found that responses to this trust question are highly correlated with experimental trust. This finding reinforces the confidence in this survey indicator for measuring generalized trust.

\section{Data analysis}

In order to assess the extent that generalized trust is related to economic freedom, Figure 1 presents an overview of the countries in our sample. In our sample the averages of economic freedom and generalized trust are 7.45 and 0.35 , respectively (see Table 1 ).

\footnotetext{
${ }^{4} \mathrm{~A}$ concise description can be found in Table A2.
} 


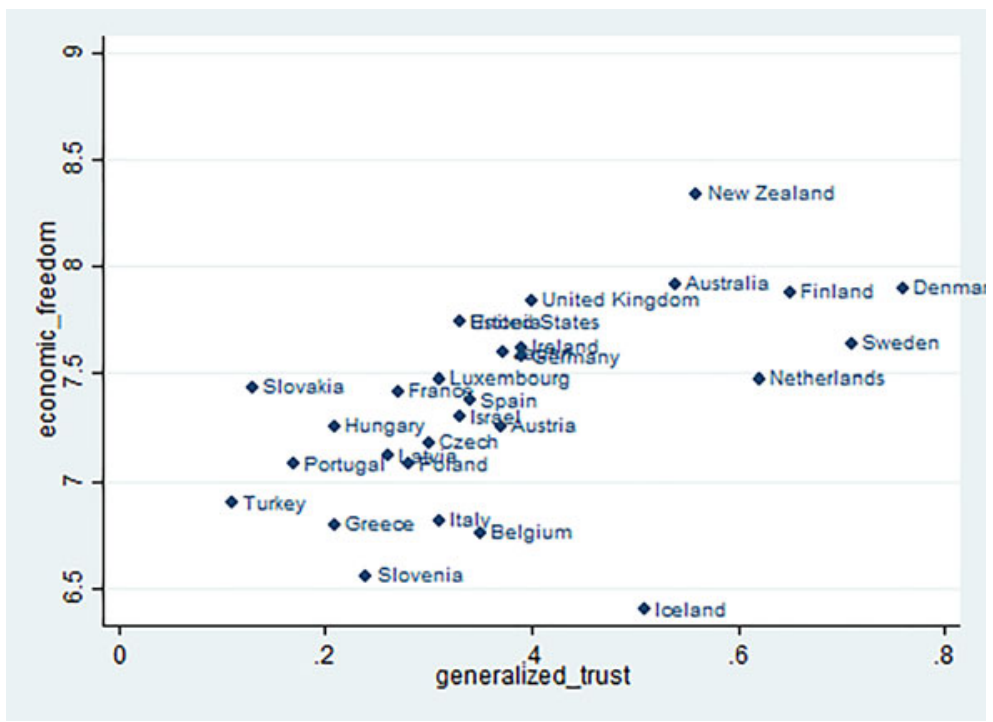

Figure 1. Economic freedom and generalized trust

Table 1. Complete list of measures, statistical descriptives, and sources

\begin{tabular}{|c|c|c|c|c|c|c|}
\hline & $N$ & Mean & SD & Min. & Max. & Source \\
\hline HDI & 725 & 0.83 & 0.06 & 0.58 & 0.94 & UN \\
\hline Income & 725 & 0.86 & 0.06 & 0.66 & 1 & UN \\
\hline Education & 725 & 0.77 & 0.10 & 0.40 & 0.94 & UN \\
\hline Life expectancy & 725 & 0.89 & 0.05 & 0.68 & 0.98 & UN \\
\hline Economic freedom & 491 & 7.45 & 0.65 & 4.50 & 8.88 & Fraser Institute \\
\hline Generalized trust & 115 & 0.35 & 0.16 & 0.05 & 0.78 & EVS/WVS \\
\hline Internal distance (In) & 725 & 4.96 & 1.00 & 2.30 & 7.08 & CEPII Database \\
\hline Temperature & 725 & 9.36 & 6.08 & -7.14 & 26.45 & $\begin{array}{l}\text { Climate Change Knowledge } \\
\text { Portal }\end{array}$ \\
\hline Dummy post-Communist & 725 & 0.20 & 0.41 & 0 & 1 & \\
\hline Dummy Scandinavia & 725 & 0.10 & 0.30 & 0 & 1 & \\
\hline Dummy monarchy & 725 & 0.35 & 0.48 & 0 & 1 & Wikipedia \\
\hline Christianity $^{\mathrm{a}}$ & 725 & 0.62 & 0.29 & 0.00 & 0.95 & PEW \\
\hline Islam $^{a}$ & 725 & 0.07 & 0.17 & 0.00 & 0.98 & PEW \\
\hline Political rights & 673 & 3.77 & 0.79 & 1 & 5 & Freedom House \\
\hline Civil liberties & 673 & 3.50 & 0.89 & 1 & 5 & Freedom House \\
\hline Urbanization & 725 & 76.09 & 12.25 & 47.92 & 100 & World Bank \\
\hline Share labor in industry & 646 & 28.21 & 5.09 & 11.72 & 40.53 & World Bank \\
\hline $\begin{array}{l}\text { Female labor participation } \\
\text { rate }\end{array}$ & 694 & 58.28 & 12.07 & 23.40 & 81.50 & World Bank \\
\hline Age structure $^{b}$ & 725 & 18.70 & 3.95 & 12.94 & 36.25 & World Bank \\
\hline
\end{tabular}

${ }^{\mathrm{a}}$ As a percentage of the total population.

${ }^{\mathrm{b}}$ Population aged $<15$ as a percentage of the total population. 
If we use these values to define low versus high economic freedom and low versus high trust, it can be noted that half of all OECD countries belong either to low trust, low economic freedom market societies or to high trust, high economic freedom societies. Only Iceland falls in the class of high trust, low economic freedom market societies, whereas several other countries belong to the class of low trust, high economic freedom market societies. The picture confirms the findings of Beugelsdijk (2006) and Cruz-Garcíal and Peiró-Palomino (2019) that trust is related to (formal) institutions. Still, Figure 1 also shows that this relationship is not one to one, as there is substantial variation in the economic freedom of countries with similar levels of trust. This indicates that other factors than economic freedom affect generalized trust. ${ }^{5}$

\section{Econometric issues}

For the regression analysis, we first standardized the dependent variables, economic freedom, and generalized trust. The nature of the panel is unbalanced because data are not available for the full sample of countries over the entire sample period. In order to test for fixed effects, we performed Hausman tests.

Whereas fixed effects substantially reduces the chance of endogeneity caused by unobserved heterogeneity between different countries, it does not solve biases that result from reverse causality. Reverse causality may bias the estimation of the effect of economic freedom on the HDI ( $\beta$ ), as socioeconomic circumstances may influence a country's adoption of the institutions of economic freedom (Berggren 1999). ${ }^{6}$ Economists have tried solving these problems by using instrumental variables (Tabellini, 2010), but the exclusion restriction remains problematic. In order to reduce the chance of simultaneity bias, we adopted two measures. First, following Bennett and Nikolaev (2017), we used economic freedom that is lagged five years. Using lagged values of the explanatory variables may address some concerns of endogeneity, as it is less likely that today's human development will reversely affect economic freedom five years ago. Second, we instrumented (five years lagged) economic freedom with the ten years lagged economic freedom (Bhattacharyya and Hodler, 2014) and used the predicted value of (five years lagged) economic freedom in testing the linear and the interacted effect of economic freedom. Since we control for fixed effects per country (which implies that $\beta$ and $\gamma$ are only identified by within-country variations of economic freedom and human development over time), this further reduces the chance that our estimations are biased by reverse causality. Still, we cannot fully exclude the possibility of reverse causality in the estimation of the influence of economic freedom on human development.

Note, however, that any remaining reverse causality in the estimation of the influence of economic freedom on human development is not likely to affect the reliability of the test results of the interacting influence of economic freedom and trust, because there are no theoretical reasons to expect any remaining simultaneity bias to be larger or smaller for high trust than for low trust countries. Therefore, the test results for $\beta$ in equation (1) or the difference between $\beta_{h}$ and $\beta_{l}$ in equation (2) are likely to be reliable.

Furthermore, as the White test indicated heteroscedasticity, we used robust standard errors for the calculation of the significance of the regression coefficients.

\section{Empirical results}

In this section we present the results of our empirical analysis. First, the bivariate correlation coefficients will be reported. Then, the multiple regression analysis will be presented.

\footnotetext{
${ }^{5}$ If we regressed generalized trust to 5 years' and 10 years' lagged economic freedom, controlling for all control variables and fixed effects, we found neither a positive nor a significant effect of economic freedom on generalized trust.

${ }^{6}$ As trust is remarkably stable in time (Bjørnskov, 2007), reverse causality from the HDI to trust is unlikely.
} 
Table 2. Bivariate correlation analysis

\begin{tabular}{lllllll}
\hline & & 1 & 2 & 3 & 4 & 5 \\
\hline 1 & HDI & 1 & & & & \\
\hline 2 & Income & 0.80 & 1 & & & \\
\hline 3 & Education & 0.89 & 0.46 & 1 & & \\
\hline 4 & Life expectancy & 0.85 & 0.78 & 0.57 & 1 & 1 \\
\hline 5 & Economic freedom & 0.56 & 0.60 & 0.42 & 0.41 & 0.43 \\
\hline 6 & Generalized trust & 0.54 & 0.52 & 0.47 & 0.44 & 1 \\
\hline
\end{tabular}

Note: Pearson correlation coefficients; italics $p<0.05$; bold $p<0.01$. The correlation coefficients for the bivariate relationship with the various control variables are available upon request with the authors.

\section{Bivariate correlation analysis}

Table 2 reports the results of the bivariate correlation analysis. Table 2 shows that economic freedom, generalized trust, and the HDI are significantly related to each other. Furthermore, we found that the HDI is positively related to internal distance, the dummy for Scandinavian countries, monarchy, Christianity, political rights, civil liberty, urbanization, and the female labor market participation rate. The HDI is negatively related to the dummy for post-communist countries, Islam, the share of labor in industry and the share of youth population in total population.

\section{Multiple regression analysis}

Table 3 reports the results of the multiple regression analysis of random and fixed effects models for the HDI as specified by equation (1). The Hausman test shows that the fixed effects model is more reliable for life expectancy (and probably also for income), whereas the random effects model is preferred for HDI and education.

We find that economic freedom is significantly and positively related to the HDI as well as to its three underlying components, income, education, and life expectancy. The interaction term of economic freedom and trust is positive and significant. These findings provide support for hypothesis 1 and reject hypotheses 2 and 3. As standardized trust ranges from -2 to +2 , the estimation results in column 1 of Table 3 imply that the marginal effect of economic freedom on the HDI varies from about $0.05(0.49-0.44)$ for low trust countries to $0.93(0.49+0.44)$ for high trust countries.

In order to test whether the models with interaction terms provide better explanations than the models without these effects, we calculated the AIC and BIC. ${ }^{7}$ In all models, dropping the interaction term substantially increased the AIC and BIC for all models, which shows that the models with the interaction term have better explanatory power. We find no significant effects for linear trust or for most other control variables. Only for age structure do we find a negative effect, whereas urbanization incidentally has a positive effect on human development in random effects models.

Table 4 reports the estimation results for the simpler model specification (2) for high trust countries and low trust countries. We define high (low) trust countries as countries for which average trust during 1990-2015 is higher (lower) than the mean value of trust during 1990-2015. Using this distinction for all years during 1990-2015, the total number of observations increases from 91 to 242.

\footnotetext{
${ }^{7}$ The Akaike Information Criterion (AIC) and the Bayesian Information Criterion (BIC) are criteria for model selection. Both apply a penalty term for the number of parameters in the model, to correct for overfitting. The model with the lowest $\mathrm{AIC} / \mathrm{BIC}$ is preferred.
} 
Table 3. Estimation results of moderated model

\begin{tabular}{|c|c|c|c|c|c|c|c|c|}
\hline & \multicolumn{2}{|c|}{ HDI } & \multicolumn{2}{|c|}{ Income } & \multicolumn{2}{|c|}{ Education } & \multicolumn{2}{|c|}{ Life expectancy } \\
\hline & 1 & 2 & 3 & 4 & 5 & 6 & 7 & 8 \\
\hline & $\mathrm{RE}$ & FE & $\mathrm{RE}$ & $\mathrm{FE}$ & $\mathrm{RE}$ & $\mathrm{FE}$ & $\mathrm{RE}$ & $\mathrm{FE}$ \\
\hline Economic freedom $_{-5}$ & $0.49^{* \star *}$ & $0.44^{\star \star \star}$ & $0.33^{\star \star \star}$ & $0.28^{\star \star \star}$ & $0.48^{\star \star \star}$ & $0.42^{\star \star \star}$ & $0.40^{\star \star \star}$ & $0.43^{\star \star \star}$ \\
\hline Generalized trust $_{-5}$ & 0.05 & -0.02 & 0.06 & -0.00 & 0.01 & $-0.09^{\star \star}$ & 0.09 & 0.12 \\
\hline $\begin{array}{l}\text { Economic freedom } \\
{ }^{\star} \text { Generalized trust } \\
-5\end{array}$ & $0.22^{\star \star}$ & $0.22^{\star \star}$ & $0.10^{\star}$ & $0.14^{\star \star}$ & $0.25^{\star \star}$ & $0.26^{\star \star}$ & $0.16^{\star \star}$ & $0.13^{\star \star}$ \\
\hline \multicolumn{9}{|c|}{ Time-invariant control variables } \\
\hline Internal distance & 0.01 & & -0.24 & & 0.14 & & -0.00 & \\
\hline Temperature & -0.01 & & 0.00 & & -0.01 & & 0.01 & \\
\hline Post-Communist & 0.09 & & $-0.99^{\star \star \star}$ & & $0.98^{\star \star \star}$ & & -0.48 & \\
\hline Scandinavia & -0.22 & & -0.10 & & -0.08 & & -0.48 & \\
\hline Monarchy & -0.17 & & -0.16 & & -0.13 & & -0.18 & \\
\hline Christian & 0.46 & & 0.36 & & 0.43 & & 0.31 & \\
\hline Muslim & 0.22 & & -0.10 & & 0.05 & & 0.72 & \\
\hline \multicolumn{9}{|l|}{ Time-variant control variables } \\
\hline Political rights & 0.02 & 0.05 & 0.02 & -0.04 & -0.03 & -0.01 & 0.11 & $0.15^{\star \star}$ \\
\hline Civil liberties & 0.11 & -0.08 & -0.07 & -0.03 & -0.10 & -0.08 & -0.09 & -0.09 \\
\hline Urbanization & $0.03^{\star \star}$ & 0.04 & $0.03^{\star \star}$ & 0.02 & $0.04^{\star \star}$ & 0.04 & 0.02 & 0.03 \\
\hline Share labor in industry & -0.01 & -0.02 & 0.01 & 0.01 & -0.02 & -0.03 & $-0.04^{\star}$ & $-0.05^{\star \star}$ \\
\hline $\begin{array}{l}\text { Female labor participation } \\
\text { rate }\end{array}$ & 0.01 & -0.00 & -0.01 & -0.01 & 0.01 & -0.01 & 0.01 & 0.01 \\
\hline Population structure & $-0.12^{\star \star \star}$ & $-0.12^{\star \star \star}$ & $-0.08^{\star \star}$ & $-0.12^{\star \star \star}$ & $-0.09^{\star \star}$ & $-0.10^{\star}$ & $-0.13^{\star \star \star}$ & $-0.09^{\star \star}$ \\
\hline$R^{2}$ (within) & 0.87 & 0.88 & 0.73 & 0.75 & 0.79 & 0.81 & 0.91 & 0.92 \\
\hline$R^{2}$ (between) & 0.76 & 0.58 & 0.75 & 0.32 & 0.70 & 0.22 & 0.63 & 0.46 \\
\hline$R^{2}$ (overall) & 0.85 & 0.73 & 0.77 & 0.39 & 0.79 & 0.44 & 0.72 & 0.61 \\
\hline$P$-value Hausman test & \multicolumn{2}{|c|}{0.128} & \multicolumn{2}{|c|}{0.051} & \multicolumn{2}{|c|}{0.161} & \multicolumn{2}{|c|}{0.015} \\
\hline$\Delta \mathrm{AIC}^{\mathrm{a}}$ & \multicolumn{2}{|c|}{-25.92} & \multicolumn{2}{|c|}{-12.52} & \multicolumn{2}{|c|}{-23.14} & \multicolumn{2}{|c|}{-12.93} \\
\hline$\Delta \mathrm{BIC}^{\mathrm{a}}$ & \multicolumn{2}{|c|}{-23.41} & \multicolumn{2}{|c|}{-10.02} & \multicolumn{2}{|c|}{-20.62} & \multicolumn{2}{|c|}{-10.42} \\
\hline
\end{tabular}

${ }^{a}$ Change in AIC and BIC caused by inclusion of interaction term of economic freedom and generalized trust.

RE: random effects. FE: fixed effects. Robust standard errors. Significance: ${ }^{\star} p<0.05,{ }^{\star \star} p<0.01,{ }^{\star \star \star} p<0.001$. Number of observations: 91 . Number of countries: 29.

Table 4 shows that in all models the estimated coefficient of economic freedom is substantially higher for high trust than for low trust countries. In the four models for the HDI and income (columns 1-4) the difference in the estimated coefficients of economic freedom between high trust and low trust countries is significant at $p=0.05$; in the four models for education and life expectancy (columns 5-8) the difference is not significant. These results provide further support for hypothesis 1 that generalized trust positively moderates the influence of economic freedom on human development, while rejecting hypothesis 2 , that trust weakens the relationship between economic freedom and human development, and hypothesis 3, that the relationship between economic freedom and human development is independent of trust. 
Table 4. Estimation results: high and low trust countries

\begin{tabular}{|c|c|c|c|c|c|c|c|c|}
\hline \multicolumn{9}{|c|}{ High trust countries $(n=97)$} \\
\hline & \multicolumn{2}{|c|}{$\mathrm{HDI}$} & \multicolumn{2}{|c|}{ Income } & \multicolumn{2}{|c|}{ Education } & \multicolumn{2}{|c|}{ Life expectancy } \\
\hline & 1 & 2 & 3 & 4 & 5 & 6 & 7 & 8 \\
\hline & $\mathrm{RE}$ & $\mathrm{FE}$ & $\mathrm{RE}$ & FE & $\mathrm{RE}$ & $\mathrm{FE}$ & $\mathrm{RE}$ & FE \\
\hline Economic freedom $_{-5}$ & $0.61^{\star \star}$ & $0.61^{*}$ & $0.42^{\star \star \star}$ & $0.44^{\star \star \star}$ & 0.60 & 0.55 & $0.52^{\star *}$ & $0.60^{\star *}$ \\
\hline (standard error) & $(0.22)$ & $(0.22)$ & $(0.09)$ & $(0.08)$ & $(0.31)$ & $(0.28)$ & $(0.18)$ & $(0.17)$ \\
\hline$P$-value Hausman test & \multicolumn{2}{|c|}{0.000} & \multicolumn{2}{|c|}{0.000} & \multicolumn{2}{|c|}{0.000} & \multicolumn{2}{|c|}{0.000} \\
\hline \multicolumn{9}{|c|}{ Low trust countries $(n=145)$} \\
\hline Economic freedom $_{-5}$ & 0.04 & 0.03 & 0.02 & 0.00 & 0.04 & 0.00 & $0.15^{*}$ & $0.17^{\star}$ \\
\hline (standard error) & $(0.06)$ & $(0.06)$ & $(0.07)$ & $(0.06)$ & $(0.09)$ & $(0.09)$ & $(0.06)$ & $(0.07)$ \\
\hline$P$-value Hausman test & \multicolumn{2}{|c|}{0.086} & \multicolumn{2}{|c|}{0.052} & \multicolumn{2}{|c|}{0.000} & \multicolumn{2}{|c|}{0.028} \\
\hline Difference is significant & + & + & + & + & - & - & - & - \\
\hline
\end{tabular}

Note: Controlled for all control variables reported in Table 3. Robust standard errors. Significance: ${ }^{\star} p<0.05,{ }^{\star \star} p<0.01,{ }^{\star \star \star} p<0.001$.

\section{Conclusions}

\section{Theoretical implications and future research}

This paper studies contingencies in the macro relationship between economic freedom and the HDI that are caused by generalized trust. Using panel analysis on a sample of 29 OECD countries for the period 1990-2015, our analysis provides indications that generalized trust positively moderates the relationship between economic freedom and human development. Generalized trust is an important cultural constituent for a flourishing society as it increases the benefits from an increase in economic freedom. This is in line with recent experimental research at the micro level by McCannon et al. (2018), who showed that individuals with higher levels of trust are more willing to enter into trade than individuals with lower levels of trust, and previous studies on interorganizational governance (Arranz and Arroyabe, 2012) that showed that trust and contract enforcement are complements rather than substitutes.

Our study suggests that research into international differences in human development should look not only at the effects of (formal) institutions in isolation, but also consider interaction with culture. Future research could identify other indicators of culture that moderate the influence of economic freedom on human development. A likely candidate is, for example, long-term orientation, which can be argued to stimulate companies and individuals to use their economic freedom to make investments that increase GDP per capita, health and education in the long term.

Another interesting topic for future research would be to discover and test hypotheses on the underlying mechanisms through which the interaction between economic freedom and generalized trust impacts human development. For example, micro studies by Gächter et al. (2004) and Balliet and Van Lange (2013) found that trust contributes to cooperation. Future research using data of the World Value Survey could test if cooperation mediates the influence of the interaction between economic freedom and trust on human development at the macro level.

Finally, it is advisable for future research to aim to disentangle the influence of the underlying components of generalized trust by testing more specifically the moderating role of personal characteristics grounded in people's emotional bonds and moral attitudes on the relationship between economic freedom and the HDI. This would provide a more proper test of the influence of this component of generalized trust by excluding the component of formal contracts. 


\section{Policy implications}

An important policy implication of our study is that countries with high economic freedom and low trust should pay more attention to the development of virtues in business life. If individuals are intrinsically motivated to have concern for others' wellbeing, then they are less inclined to make use of opportunities to break agreements and benefit financially (McCannon et al., 2018). If policy makers liberalize their economy in a situation of low trust, institutional misalignments emerge. The improved formal framework will then not generate the economic benefits that people expect from them, as a lack of cultural values might hamper entrepreneurial actions. Virtuousness in economic actors is therefore an important condition for societal acceptance of free markets. If companies cannot be trusted, society expects that more negative externalities will result from free market operations and support for free market operations decreases. If citizens come to expect higher risks and costs because companies develop unfair practices by abusing information asymmetry, citizens will support (more) government regulation (Aghion et al., 2010; Djankov et al., 2003; Glaeser \& Shleifer, 2003; Pinotti, 2012).

Second, countries with high trust but low economic freedom could improve their performance by raising the quality of the protection of property rights. If formal contracts that specify the duties of both parties are backed by a good juridical system, this will mitigate opportunistic behavior that might be invited by the trust of others (Arranz and de Arroyabe, 2012). Furthermore, Graafland and Compen (2015) have shown that generalized trust increases with the property rights dimension of economic freedom, whereas it decreases with low government spending and low taxes. When improving the protection of property rights, governments thus catch two birds in one stroke, as it will increase both generalized trust and economic freedom. Lowering government spending and taxes is a less attractive way of increasing economic freedom, as the positive effect on the HDI from the increase in economic freedom might be diminished by a negative effect from a decrease in generalized trust.

\section{Limitations}

It should be stressed that the scope of the empirical research in this study is limited because of data restrictions. First, the study is limited to the period of 1990 to 2015, when liberalization was in vogue (in contrast to the preceding period of 1950s-1980s with heavy government-sponsored infrastructure investments). Furthermore, the focus on OECD countries reduces the heterogeneity between the countries studied. This limits the generalizability of the findings of the study. When more data become available in the future, the robustness of the findings of our explorative study should therefore be tested for a broader set of countries and time spans.

Acknowledgments. The author thanks Lans Bovenberg, Eelke de Jong, Jens Prüfer and four reviewers for their comments on an earlier version of this paper. This work was supported by the Templeton World Charity Foundation, Inc. Templeton World Charity Foundation had no involvement in the study design; collection, analysis and interpretation of data; in the writing of the report; and in the decision to submit the article for publication.

\section{References}

Aghion, P., Y. Algan, P. Cahuc and A. Shleifer (2010), 'Regulation and Distrust', Quarterly Journal of Economics, 125: 10151049.

Ahlerup, P., O. Olsson and D. Yanagizawa (2009), 'Social Capital vs Institutions in the Growth Process', European Journal of Political Economy, 25(1): 1-14.

Aixalá, J. and G. Fabro (2009), 'Economic Freedom, Civil Liberties, Political Rights and Growth: A Causality Analysis', Spanish Economic Review, 11(3): 165-178.

Aksoy, B., H. Harwell, A. Kovaliukaite and C. Eckel (2018), 'Measuring Trust: A Reinvestigation', Southern Economic Journal, 84(4): 992-1000.

Alesina, A. and P. Giuliano (2015), 'Culture and Institutions', Journal of Economic Literature, 53(4): 898-944.

Algan, Y. and P. Cahuc (2014), 'Trust, Growth, and Well-being: New Evidence and Policy Implications', In P. Aghion and S. N. Durlauf (ed.) Handbook of Economic Growth (Volume 2A), Amsterdam and San Diego: Elsevier, pp. 49-120. 
Arranz, N. and J. C. F. de Arroyabe (2012), 'Effect of Formal Contracts, Relational Norms and Trust on Performance of Joint Research and Development Projects', British Journal of Management, 23(4): 575-588.

Azman-Saini, W. N. W., A. Z. Baharumshah and S. H. Law (2010), 'Foreign Direct Investment, Economic Freedom and Economic Growth: International Evidence', Economic Modelling, 27(5): 1079-89.

Balliet, D. and P. A. van Lange (2013), 'Trust, Conflict, and Cooperation: A Meta-analysis', Psychological Bulletin, 139(5): 1090-1112.

Bennett, D. and B. Nikolaev (2017), 'On the Ambiguous Economic Freedom-Inequality Relationship', Empirical Economics, 53(2): 717-754.

Bennett, D. L., H. Faria, J. D. Gwartney and D. R. Morales (2017), 'Economic Institutions and Comparative Economic Development: A Post-colonial Perspective’, World Development, 96: 503-519.

Berggren, N. (1999), 'Economic Freedom and Equality: Friends or Foes?' Public Choice, 100(3-4): 203-223.

Berggren, N. and H. Jordahl (2006), 'Free to Trust: Economic Freedom and Social Capital', Kyklos, 59(2): 141-169.

Beugelsdijk, S. (2006), 'A Note on the Theory and Measurement of Trust in Explaining Differences in Economic Growth', Cambridge Journal of Economics, 30(3): 371-387.

Bhattacharyya, S. and R. Hodler (2014), 'Do Natural Resource Revenues Hinder Financial Development? The Role of Political Institutions', World Development, 57: 101-113.

Bisin, A. and T. Verdier (2017), 'On the Joint Evolution of Culture and Institutions', NBER working paper 23375, available at www.nber.org/papers/w23375 (accessed 3 October 2019).

Bjørnskov, C. (2007), 'Determinants of Generalized Trust: A Cross-country Comparison', Public Choice, 130(1-2): 1-21.

Bjørnskov, C. (2012), 'How does Social Trust Affect Economic Growth?' Southern Economic Journal, 78(4): $1346-1368$.

Bjørnskov, C. and N. J. Foss (2008), 'Economic Freedom and Entrepreneurial Activity: Some Cross Country Evidence', Public Choice, 134(3): 307-328.

Bjørnskov, C., A. Dreher and J. Fischer (2008), 'Cross-country Determinants of Life Satisfaction: Exploring Different Determinants across Groups in Society', Social Choice and Welfare, 30(1): 119-173.

Bowles, S. (2011), 'Is Liberal Society a Parasite on Tradition?' Philosophy \& Public Affairs, 39(1): 46-81.

Boyd, R. and P. J. Richerson (2005), The Origin and Evolution of Cultures, Oxford: Oxford University Press.

Cruz-García, P. and J. Peiró-Palomino (2019), 'Informal, Formal Institutions and Credit: Complements or Substitutes?', Journal of Institutional Economics. doi: 10.1017/S1744137419000018.

De Haan, J., S. Lundström and J. E. Sturm (2006), 'Market-oriented Policies and Economic Growth: A Critical Survey', Journal of Economic Surveys, 20(2): 157-192.

Djankov, S., E. Glaeser, R. La Porta, F. Lopez-de-Silanes and A. Shleifer (2003), 'The New Comparative Economics', Journal of Comparative Economics, 31(4): 595-619.

Farhadi, M., M. R. Islam and S. Moslehi (2015), 'Economic Freedom and Productivity Growth in Resource-rich Economies', World Development, 72: 109-126.

Feldmann, H. (2017), 'Economic Freedom and Human Capital Investment', Journal of Institutional Economics, 13(2): 421-445.

Friedman, M. (1999), 'The Business Community's Suicidal Impulse', Cato Policy Report, 21(2): 6-7.

Frijters, P., J. P. Haisken-DeNew and M. A. Shields (2005), 'The Causal Effect of Income on Health: Evidence from German Reunification', Journal of Health Economics, 24(5): 997-1017.

Fukuyama, F. (1995), Trust: The Social Virtues and the Creation of Prosperity, New York: Free Press.

Gächter, S., B. Herrmann and C. Thöni (2004), 'Trust, Voluntary Cooperation, and Socio-economic Background: Survey and Experimental Evidence', Journal of Economic Behavior \& Organization, 55(4): 505-531.

Gardner, J. and A. Oswald (2007), 'Money and Mental Wellbeing: A Longitudinal Study of Medium-sized Lottery Wins', Journal of Health Economics, 26(1): 49-60.

Glaeser, E. and A. Shleifer (2003), 'The Rise of the Regulatory State', Journal of Economic Literature, 41(2): 401-425.

Graafland, J. J. and B. Compen (2015), 'Economic Freedom and Life Satisfaction: Mediation by Income per Capita and Generalized Trust', Journal of Happiness Studies, 16(3): 789-810.

Graafland, J. and B. Lous (2018), 'Economic Freedom, Income Inequality and Life Satisfaction in OECD Countries', Journal of Happiness Studies, 19(7): 2071-2093.

Guiso, L., P. Sapienza and L. Zingales (2006), 'Does Culture Affect Economic Outcomes?' Journal of Economic Perspectives, 20(2): 23-48.

Gwartney, J. (2009), 'Institutions, Economic Freedom, and Cross-country Differences in Performance', Southern Economic Journal, 75(4): 937.

Gwartney, J., J. Hall and R. Lawson (2017), 'Economic Freedom of the World: 2017 Annual Report', retrieved April 19, 2018, from https://www.fraserinstitute.org/studies/economic-freedom-of-the-world-2017-annual-report (accessed 3 October 2019).

Hall, J. C. and L. A. Lawson (2014), 'Economic Freedom of the World: An Accounting of the Literature', Contemporary Economic Policy, 32(1): 1-19. 
Hall, J. C., R. S. Sobel and G. R. Crowley (2010), 'Institutions, Capital, and Growth', Southern Economic Journal, 77(2): 385405.

Hayek, F. (1948), Individualism and Economic Order, Chicago: University of Chicago Press.

Helliwell, J. F. and R. D. Putnam (2004), 'The Social Context of Well-being', Philosophical Transactions of the Royal Society of London: Series B, Biological Sciences, 359(1449): 1435-1446.

Hofstede, G., G. J. Hofstede and M. Minkov (2010), Cultures and Organizations: Software of the Mind (revised and expanded 3rd edn), New York: McGraw-Hill.

Jen, M. H., E. R. Sund, R. Johnston and K. Jones (2010), 'Trustful Societies, Trustful Individuals, and Health: An Analysis of Self-rated Health and Social Trust Using the World Value Survey', Health \& Place, 16(5): 1022-1029.

Jiang, X., M. Li, S. Gao, Y. Bao and F. Jiang (2013), 'Managing Knowledge Leakage in Strategic Alliances: The Effects of Trust and Formal Contracts', Industrial Marketing Management, 42(6): 983-991.

Justesen, M. K. (2008), 'The Effect of Economic Freedom on Growth Revisited: New Evidence on Causality from a Panel of Countries, 1970-1999', European Journal of Political Economy, 24(3): 642-660.

King, E. M., C. E. Montenegro and P. F. Orazem (2012), 'Economic Freedom, Human Rights, and the Returns to Human Capital: An Evaluation of the Schultz Hypothesis', Economic Development and Cultural Change, 61(1): 39-72.

Knack, S. and P. Keefer (1997), 'Does Social Capital Have an Economic Payoff? A Cross-country Investigation', Quarterly Journal of Economics, 112(4): 1251-1288.

Leigh, A. (2006), 'Trust, Inequality and Ethnic Heterogeneity', Economic Record, 82(258): 268-280.

Lucas, R. E. (2000), 'Some Macroeconomics for the $21^{\text {st }}$ century', Journal of Economic Perspectives, 14(1): 159-168.

Masten, E. and J. Prüfer (2014), 'On the Evolution of Collective Enforcement Institutions: Communities and Courts', Journal of Legal Studies, 43(2): 359-400.

Mayer, T. and S. Zignago (2011), 'Notes on CEPII's Distances Measures: The GeoDist Database', CEPII Working Paper 2011-25.

McCannon, B. C., C. Tokar Asaad and M. Wilson (2018), 'Contracts and Trust: Complements or Substitutes?' Journal of Institutional Economics, 14(5): 811-832.

Murphy, R. H. (2016), 'Economic Freedom of North America at State Borders', Journal of Institutional Economics, 12(4): 885-893.

Nikolaev, B. (2014), 'Economic Freedom and Quality of life: Evidence from the OECD's Your Better Life Index', Journal of Private Enterprise, 29(3): 61-96.

North, D. C. (1991), 'Institutions', Journal of Economic Perspectives, 5(1): 97-112.

Nyström, K. (2008), 'The Institutions of Economic Freedom and Entrepreneurship: Evidence from Panel Data', Public Choice, 136(3-4): 269-282.

Özcan, B. and C. Bjørnskov (2011), 'Social Trust and Human Development', Journal of Socio-Economics, 40(6): 753-762.

Papagapitos, A. and R. Riley (2009), 'Social Trust and Human Capital Formation', Economics Letters, 102(3): 158-160.

Pinotti, P. (2012), 'Trust, Regulation, and Market Failures', Review of Economics and Statistics, 94(3): 650-658.

Poppo, L. and T. Zenger (2002), 'Do Formal Contracts and Relational Governance Function as Substitutes or Complements?' Strategic Management Journal, 23(8): 707-725.

Preacher, K. J., D. D. Rucker and A. F. Hayes (2007), 'Addressing Moderated Mediation Hypotheses: Theory, Methods, and Prescriptions', Multivariate Behavioral Research, 42(1): 185-227.

Putnam, R. D. (1993), 'The Prosperous Community', American Prospect, 4(13): 35-42.

Rostila, M. (2007), 'Social Capital and Health in European Welfare Regimes: A Multilevel Approach', Journal of European Social Policy, 17(3): 223-239.

Rothstein, B. (2000), 'Trust, Social Dilemmas, and Collective Memories', Journal of Theoretical Politics, 12(4): 477-501.

Rousseau, D. M., S. B. Sitkin, R. S. Burt and C. Camerer (1998), 'Not So Different after All: A Cross-discipline View of Trust', Academy of Management Review, 23(3): 393-404.

Schofer, E. and J. W. Meyer (2005), 'The Worldwide Expansion of Higher Education in the Twentieth Century', American Sociological Review, 70(6): 898-920.

Sen, A. K. (1984), Resources, Values and Development, Oxford: Blackwell.

Spruk, R. and A. Kešeljević (2018), 'Economic Freedom and Growth across German Districts', Journal of Institutional Economics, 14(4): 739-765.

Stroup, M. D. (2007), 'Economic Freedom, Democracy, and the Quality of Life', World Development, 35(1): 52-66.

Tabellini, G. (2008), ‘The Scope of Cooperation: Values and Incentives', Quarterly Journal of Economics, 123(3): 905-950.

Tabellini, G. (2010), 'Culture and Institutions: Economic Development in the Regions of Europe', Journal of the European Economic Association, 8(4): 677-716.

Weitz, B. A. and K. D. Bradford (1999), 'Personal Selling and Sales Management: A Relationship Marketing Perspective', Journal of the Academy of Marketing Science, 27(2): 241-254. 


\section{Appendix}

Table A1. Countries included in the sample

\begin{tabular}{|c|c|c|c|c|}
\hline \multicolumn{2}{|c|}{ Western Europe } & \multirow{2}{*}{$\begin{array}{l}\text { Central Europe } \\
\text { Czech Republic }\end{array}$} & \multirow{2}{*}{$\begin{array}{l}\text { North America } \\
\text { United States }\end{array}$} & \multirow{2}{*}{$\begin{array}{r}\text { Other } \\
\text { Australia }\end{array}$} \\
\hline Austria & Ireland & & & \\
\hline Belgium & Italy & Estonia & & Japan \\
\hline Denmark & Luxembourg & Hungary & & New Zealand \\
\hline Finland & Netherlands & Latvia & & Singapore \\
\hline France & Portugal & Poland & & Turkey \\
\hline Germany & Spain & Slovakia & & \\
\hline Greece & Sweden & Slovenia & & \\
\hline Iceland & United Kingdom & & & \\
\hline 16 & & 7 & 1 & 5 \\
\hline
\end{tabular}

Table A2. Dimensions of economic freedom index of Fraser Institute

\begin{tabular}{|c|c|}
\hline Areas of economic freedom & Sub-indicators \\
\hline Fiscal freedom & $\begin{array}{l}\text { 1. Fiscal freedom (Top marginal income rate and payroll tax rate) } \\
\text { 2. Transfers and subsidies } \\
\text { 3. Government enterprises and investment } \\
\text { 4. Top marginal tax rate }\end{array}$ \\
\hline Legal system and property rights & $\begin{array}{l}\text { 1. Judicial independence } \\
\text { 2. Impartial courts } \\
\text { 3. Protection of property rights, } \\
\text { 4. Military interference in rule of law and politics } \\
\text { 5. Integrity of legal system, } \\
\text { 6. Legal enforcement of contracts } \\
\text { 7. Regulatory costs of the sale of real property } \\
\text { 8. Reliability of police } \\
\text { 9. Business costs of crime }\end{array}$ \\
\hline Access to sound money & $\begin{array}{l}\text { 1. Money growth } \\
\text { 2. Standard deviation of inflation, } \\
\text { 3. Inflation most recent year } \\
\text { 4. Freedom to own foreign currency accounts }\end{array}$ \\
\hline Freedom to trade internationally & $\begin{array}{l}\text { 1. Tariffs } \\
\text { 2. Regulatory barriers } \\
\text { 3. Size of trade sector relative to potential } \\
\text { 4. Black-market exchange rates } \\
\text { 5. Controls of the movement of capital and people }\end{array}$ \\
\hline Freedom from regulation & $\begin{array}{l}\text { 1. Credit market regulations } \\
\text { 2. Labor market regulations } \\
\text { 3. Business regulations }\end{array}$ \\
\hline
\end{tabular}

Source: www.freetheworld.com/2015/economic-freedom-of-the-world-2015.pdf (accessed 3 October 2019).

Cite this article: Graafland J (2020). Contingencies in the relationship between economic freedom and human development: the role of generalized trust. Journal of Institutional Economics 16, 271-286. https://doi.org/10.1017/S1744137419000705 